Vol.59: e16160503, January-December 2016 http://dx.doi.org/10.1590/1678-4324-2016160503 ISSN 1678-4324 Online Edition

BRAZILIAN ARCHIVES OF BIOLOGY AND TECHNOLOGY

AN INTERNATIONAL JOURNAL

\title{
Research on Value Assessment and Compensation for Health Hazards of Urban Air Pollution-A Case Study of Urumqi
}

\author{
Chen $\mathrm{Yu}^{1^{*}}$; Sun Hui ${ }^{2}$. \\ ${ }^{1}$ School of Public Health,Xinjiang Medical University,Urumqi; ${ }^{2}$ Innovation Management Research Center,Xinjiang \\ University, University, Urumqi.
}

\begin{abstract}
With the acceleration of urbanization and industrialization, urban air pollution has become a serious threat to the health of urban residents. In this study, to investigate health hazards caused by air pollution for urban residents, concentrations of main air pollutants and annual coal consumption amounts during the period from 2000 to 2013 were analyzed. Our results showed that economic losses of Urumqi caused by air pollution amounted to 63.155 million yuan in 2013, accounting for $0.2 \%$ of its GDP and 5.7\% of public utility expenditures for that year. The compensation mechanism analysis suggested that it is necessary to further improve the health care system and increase corporate environmental taxes. More environmental health protection taxes should be levied on key monitoredenterprises in Urumqi to achieve effective compensations for urban residents affected by air pollutionrelated health hazards.
\end{abstract}

Keywords: air pollution; health hazard; compensation

\footnotetext{
*Authors for correspondence: shui@xju.edu.cn
} 


\section{CLC: F426 Document Code: A Paper ID:}

With the acceleration of urbanization and industrialization, air pollution, especially in urban areas, has become increasingly serious and turned into a global challenge. Health hazards are the most serious negative impacts caused by air pollution in urban areas. At present, particulate matters emitted to air are 100 million tons per year(Adel,2015). The increasingly poor air quality has directly generated health hazards for urban residents. World Health Organization has reported that about 1.6 million people are suffering from bad consequences of air pollution in urban areas( Ayres-Sampaio et al., 2014), and an average of hundreds of thousands of people die earlier than expected each year due to air pollution. Because of air pollution, tens of millions people suffer various types of acute and chronic diseases(Xue et al.,2008). Besides the respiratory system directly affected by air pollutants, the immune system, cardiovascular and nervous systems are subjected to different degrees of damage. However, due to the lack of relevant legal systems and the imperfection of health care system, currently there is no compensation mechanism for air pollutionrelated health hazards(Wang,2000). As a result, no people or agency compensates for huge disease burdens and economic losses caused by air pollution to urban residents. In recent years, as ecological environmental issues have gradually become major important factors restraining sustainable economic development in China, ecological compensation has received growing attention from government and society. However, no consensus has been reached on the measurement, calculation and identification of compensations for health hazards. Herein we analyzed health hazards of air pollution for urban residents, measured and calculated health economic burdens brought by air pollution, and designed compensation modes and standards for health hazards. Our results can provide a basis for governments to further improve the ecological compensation mechanism and develop more comprehensive ecological compensation standards in the future.

\section{Literature Review}

Since the 1940s, the economic analysis of environment has received wide attention from the academia. Researches have been done to analyze the environmental economic losses from different aspects. Former Soviet economist Strumilin.S.G was the first to propose that environmental economic research should be a combination of environment, ecology, resource and economy(Lipfert, 1993). Other researchers suggested that the social cost of urban pollution should be deducted from GDP, and Net Economic Welfare Indicators were introduced (Leipert,1987; Sefton et al.,1996). In 1973, Japanese government set the environmental pollution as one of the indicators for the net national welfare. The excessive pollution according to the national standard shall be tackled and the cost occurred must be deducted from GDP (Bale.,1978). In the mid-1970s, United States estimated that the annual economic loss due to environmental pollution was $\$ 50$ billion or $5 \%$ of the GDP(William,2003). Ridker was considered the first scholar to evaluate the economic losses resulted from air-pollutionrelated human health issues. He used a human capital approach to calculate the monetary loss of United States due to a variety of diseases and death caused by air pollution in 1958 (Ridker,1967). Subsequently, willingness investigation model, atmospheric pollutant model, and dose-response human health model were developed to calculate the health damage cost of air pollution in other countries(Burnett et al.1999; Cannon,1990). Chinese researches on the economic cost of environmental pollution could be traced back to 1981, when the theory and method of economic losses caused by pollution were reported for the first time. Valuation method, disease costing method, human capital and other methods were later adopted to evaluate the health damage caused by air pollution in Shanghai, Xi'an and Beijing(Zhao et al.,2014; Kan et al.,2004; Xu et al.,2007). In addition, in the field of ecological compensation, in-depth theoretical studies were widely conducted. Previous scholars believed that the standard amount of ecological compensation should be closely related to the provider's opportunity cost (Macmillan, 1998), and the connotation of ecological compensation should include the compensation for losses of human health caused by the ecological damage(Lebedev,1997). Chinese scholars have made certain progresses in studying ecological compensation regarding forests, rivers, pastures 
and other areas (Li et al.,2009). In this field, the focus of compensation has been shifted to the health sector(Li,2008). In summary, health hazards of air pollution and its ecological compensations have attracted worldwide attention. A lot of methods and theories have been developed, allowing us to use mixed methods to study the different aspects of air pollution-associated issues. However, most studies are focused on the assessment of health hazard size of environmental pollution and estimation of economic losses, but not on the compensation modes for economic losses, compensation standards and other related issues. In addition, currently there are only a few studies conducted in China, which are based on data from Beijing, Shanghai and other first-tier cities. These research results obtained from limited geographical regions thus cannot serve as a reference for other cities. Therefore there is an urgent need to study economic losses caused by air pollution and their compensation mechanism in the industry-dependent, fast growing, middlelevel-development cities in China.

Urumqi is a typical industry-dependent second-tier city with over 200 industrial and mining industries. In recent years, along with the rapid economic development, Urumqi has faced serious air pollution problems due to the increase in the proportion of secondary industries and heavy industry pollution sources. As a result, the incident of diseases caused by air pollution has increased year by year. The findings in Urumqi can provide a basis and reference to other second-tier cities in developing relevant policies. In this study, we chose the established semi-parametric GAM with time series, mature human capital method and disease cost method to measure and calculate health economic losses caused by air pollution. GAM is one of the important methods used in ecological analyses and has been widely used (Freitas et al.,2009.). It can build appropriate statistical relationship between a series of observed variables and environmental indexes. Because GAM is a model that changes with selected data, using GAM to estimate the relative risk of air pollution to the health effect terminal can better reflect the relationship between dependent variables and independent variables. Health economic losses are classified into three types: death economic losses, chronic disease economic losses and other disease economic losses. Different methods can be used to calculate the health economic losses caused by air pollution.
For our study, in addition to the human capital method and disease cost method, the disease incapacitation method was also introduced to measure and calculate disease economic losses. These approaches might allow us to obtain the most accurate calculation results and provide a scientific basis and reference for developing effective pollution control and compensation plans in the next stage.

\section{Analysis of Air Pollution and Resident Health Conditions in Urumqi}

Urumqi, located at the foot of Tian Mountain, and the southern margin of Junggar Basin in the hinterland of the Eurasian continent, is an important gateway to the opening of western China. Urumqi has suffered serious air pollution caused by urban functional layout, energy structure and other factors. Currently, there are over 200 industrial and mining enterprises in Urumqi, which has developed into a modern city that relies on coal, iron and steel, chemicals, petroleum processing, power, textile, construction, building materials, paper and other sectors. An inefficient and wasteful energy use and the coaloriented urban energy structure are the main factors causing air pollution in Urumqi. In addition, special geographical and meteorological conditions in Urumqi prevent the diffusion and dilution of air pollutants, thus restraining its selfpurification capacity. According to the statistics, air pollution conditions of Urumqi during the period from 2000 to 2013 can be roughly divided into three stages (Figure 1). The period from 2000 to 2004 is classified as the first stage. During this stage, due to the development of western China, a series of large-scale heavy industry projects were launched, which caused Urumqi to suffer high concentrations of air pollution. In particular, the concentrations of large particulates were above the national severe pollution standard for a long time. The coal consumption was also increased rapidly. Urumqi was listed as one of most seriously polluted cities at this stage. After the first-stage "Blue Sky Project" was launched in 2002, concentrations of urban air pollutants such as $\mathrm{PM}_{10}$ began to decline and dropped to the lowest point in 2004, making the air quality of Urumqi better than the secondary standards according to "China Ambient Air Quality Standards". At the second stage (2005-2011), Urumqi witnessed a slight deterioration of its air quality, mainly because the number of motor vehicles has risen sharply during 
that time. To make it even worse, the problem of heating boiler coal consumption was not fundamentally resolved, causing the growth rate of coal consumption to be at an all-time high level. The average concentration of air pollutants was around $0.14 \mathrm{mg} / \mathrm{m}^{3}$. At the third stage $(2012$ 2013), Urumqi invested 2.5 billion RMB on the "coal to gas" project in the winter heating period in 2012, which significantly decreased its coal consumption and dramatically improved its air quality in the winter. There was also a further decline in its annual average concentration of air pollutants. However, its air quality still failed to meet the secondary standards. As shown in Figure
2, although the number of standard days slightly rose, the number of severe pollution days increased significantly. In summary, Urumqi experienced an improvement in its air quality, but still suffered serious pollution. The major pollutants included $\mathrm{PM}_{10}$ and $\mathrm{SO}_{2}$, followed by $\mathrm{NO}_{2}$. Based on the projected continuous expansion in the size of Urumqi, progressive increase in its urban population and continuous rise in energy consumption volumes, Urumqi would face increasingly great environmental pressures. It is thus urgent to pay more attention to health conditions of Urumqi residents.

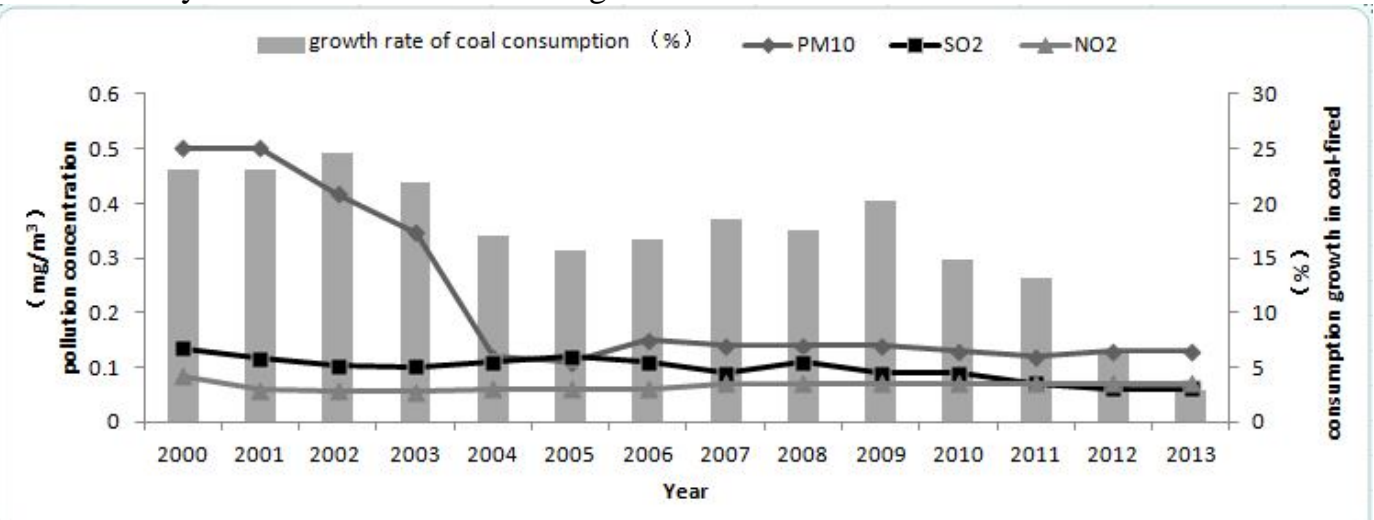

Figure 1. The concentrations of major air pollutants and the growth of coal consumption in Urumqi (2000-2013)

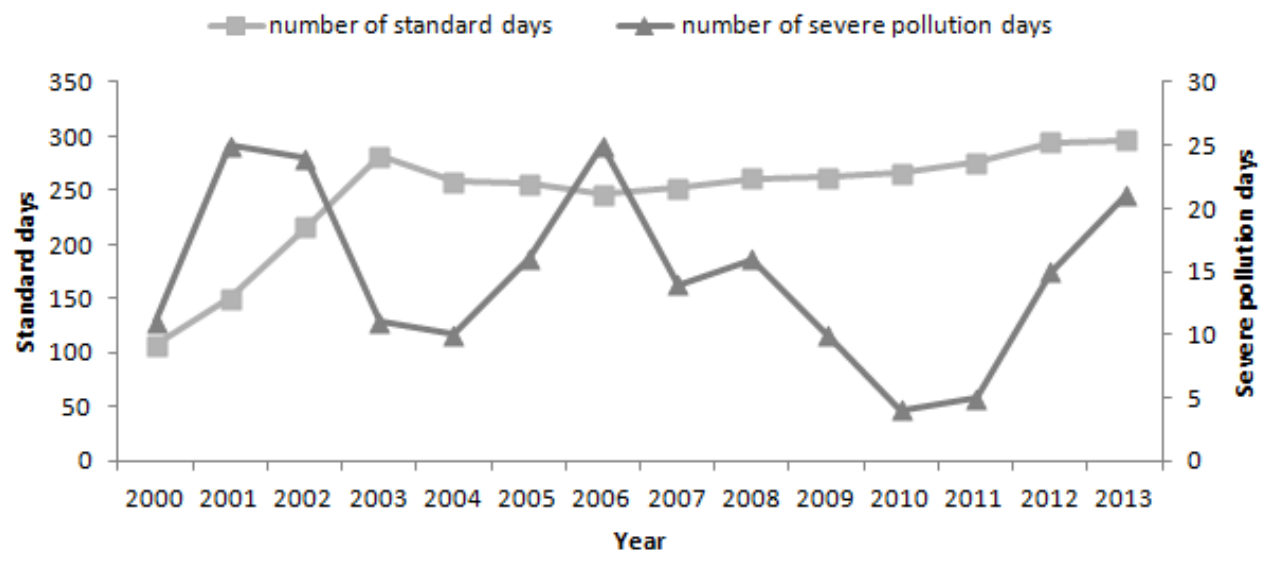

Figure 2. Statistics about air quality in Urumqi (2000-2013)

Econometric models and data sources

\section{Index Selection}

According to the 2010 Environmental Quality Bulletin issued by the Ministry of Environmental Protection, about $62 \%$ of residents were exposed to air pollution in urban areas. Therefore, $62 \%$ was taken as the exposed population proportion, and the overall population of Urumqi was taken as the exposed population base for this study. Based on the previous analysis of air pollution conditions of Urumqi, $\mathrm{PM}_{10}$ and $\mathrm{SO}_{2}$, two major air pollutants, were chosen as the observed indexes of air pollutants for the calculation of disease economic losses. The selection of effect terminals was based 
on the effect standards of some pollutants on human health (Table 1) released by the EPA's Office of Air Quality and Standards in May 2002(USEPA Office of Air and Radiation, Office of Air Quality Planning,2002), and the selections of health hazard terminals of air pollution for Beijing, Shanghai, Datong, Chongqing and other
cities(Kan et al., 2002; Xu et al.,2013; Li et al.,2007.). In this study, cardiovascular disease mortality, respiratory disease mortality, chronic bronchitis mortality, acute bronchitis mortality, emphysema mortality, and asthma mortality were chosen as the air pollution health hazard terminals for urban residents in Urumqi.

Table 1. Impact of major air pollutants on human health

\begin{tabular}{ll}
\hline Pollutants & Health hazards \\
\hline $\mathrm{PM}_{10}$ & $\begin{array}{l}\text { Aggravating respiratory and cardiovascular diseases } \\
\text { Causing temporary breathing disorders, respiratory diseases and lung } \\
\text { damages }\end{array}$ \\
$\mathrm{SO}_{2}$ & Increasing the incident of respiratory diseases \\
$\mathrm{NO}_{2}$ &
\end{tabular}

\section{Econometric Models}

Dose-response model of air pollution

The Dose-Response Technique establishes a link between the changes in concentrations of air pollutants and the changes in health effect terminals of the exposed population, thus laying a basis for making a quantitative evaluation of health hazards caused by air pollution. The occurrence of various diseases belongs to the small probability event, following the Poisson distribution. Therefore, the risk factor assessment model of the Poisson regression is introduced into the general form of GAM to build the healthdamaging exposure-response model of pollutants as:

$$
\left.\log E\left(Y_{j}\right)\right\rfloor=a+D O W+\mu X_{j}+s(\text { time, } d f)+s\left(Z_{j} d f\right)
$$

where $\mathrm{E}(\mathrm{Yj})$ is the expected number (replaced by the average number in the sampling areas obtained in the fourth health service survey) of patients admitted to hospitals in the (j) day; $\mathrm{Yj}$ is the number of patients who are admitted to hospitals due to a health effect terminal in the (j) day; $a$ is a constant term of intercept; DOW is a weekend variable; $\mu$ is the exposure-response relationship coefficient; $\mathrm{Xj}$ is the concentrations of air pollutants in the (j) day; $s$ is a non-parametric spline smooth function; time is the time variable; df is the degree of freedom; and $\mathrm{Zj}$ is the meteorological factor variable in the $(\mathrm{j})$ day.

\section{Estimate of relative risks}

After $\mu$ is obtained using the dose-response model of air pollution (Equation 1), relative risks (RR) of different effect terminals along with per unit concentration change in pollutants can be calculated as:

$$
R R_{K}=\ln \frac{\mu}{\Delta G}=\ln \frac{\mu}{G-G_{0}}
$$

where $\mathrm{RR}_{\mathrm{k}}$ is the relative risk of the pollutant (k); $\mu$ is the exposure-response relationship coefficient; $\mathrm{G}$ is the actual concentration of pollutants; and $\mathrm{G}_{0}$ is the threshold pollutant concentration that would not produce health hazards, i.e., secondary standards developed in "China Ambient Air Quality Standards" $\left(0.1 \mathrm{mg} / \mathrm{m}^{3}\right.$ for $\mathrm{PM}_{10}$ and 0.06 $\mathrm{mg} / \mathrm{m}^{3}$ for $\mathrm{SO}_{2}$ ).

The corresponding confidence intervals (CI) at the $95 \%$ level can then be calculated.

\section{Calculation of the number of people in health terminals}

The number of people in health hazard terminals caused by air pollution can be calculated as:

$$
C_{K}=P \times M_{K} \times R R_{K} \times\left(\sqrt{G}-\sqrt{G_{0}}\right)
$$

where $C_{K}$ is variation in health effects of the $(k)$ terminals caused by air pollution; $\mathrm{P}$ is the exposed population (the total population in a city); $\mathrm{M}_{\mathrm{k}}$ is the incidence of the $(\mathrm{k})$ health effect terminals; $R_{K}$ is the relative risk of the pollutant $(K) ; G$ is the actual concentration of pollutants; and $\mathrm{G}_{0}$ is the threshold pollutant concentration that would not produce health hazards.

Models for calculation of health economic losses 
Common methods used for calculating health economic losses include the disease cost method, the modified human capital method and the method of willingness to pay (WTP), each of which have their own advantages. In this study, to calculate health economic losses, health economic losses were further divided into death economic losses, chronic disease economic losses, and other disease economic losses. The modified human capital method was used to calculate economic losses caused by earlier deaths (Equation 4). Chronic diseases have greater impacts on human health, as chronic disease patients would endure lifelong torment, which would exert a long-term impact on their quality of life. Therefore, the disease incapacitation method was adopted to assess economic losses of chronic diseases caused by air pollution (Equation 5). The disease cost method was chosen to estimate economic losses caused by other diseases (Equation 6 ).

$$
H_{t}=\sum_{n=1}^{m} G D P_{d c n}^{P V}=G D P_{d c 0} \times \sum_{n=1}^{m} \frac{(1+\lambda)^{m}}{(1+r)^{m}}
$$

In Equation (4), $\mathrm{H}_{\mathrm{t}}$ is the per capita human capital loss; $\mathrm{m}$ is the per capita losing lifetime; $G D P_{d c n}^{p v}$ is the per capita GDP discounted present value in the future (n) year; $G D P_{d c 0}$ is the per capita GDP of the base year (that is, the per capita GDP in 2013); $\lambda$ is the per capita GDP growth rate; and $r$ is the social discount rate (replaced by the one-year loan interest rate of banks).

$B_{I}=a \times \delta \times H_{t}$

In Equation (5), $\mathrm{B}_{1}$ is economic losses of chronic bronchitis; $\mathrm{a}$ is the incapacitation weight of chronic bronchitis; $\delta$ is the number of patients suffering chronic bronchitis; and $\mathrm{Ht}$ is the per capita human capital losses caused by chronic bronchitis.

$$
B_{2}=\sum_{k}\left(C_{k} \times F_{k}\right)
$$

In Equation (6), $\mathrm{B}_{2}$ is economic losses caused by acute bronchitis, emphysema and asthma; $\mathrm{C}_{\mathrm{k}}$ is the number of patients suffering the disease $(\mathrm{k})$; and $\mathrm{F}_{\mathrm{k}}$ is the average medical costs of the disease (k).

\section{Data Sources}

In this study, relevant data was collected from "Xinjiang Statistical Yearbook (2005-2011)", "Urumqi Statistical Yearbook (2005-2011)", "2013 China City Statistical Yearbook" and "Fourth Health Service Survey". Annual average concentration values of environmental pollutants from 2000 to 2013 and daily data about air pollutants in 2013 were obtained from annual reports released by the Municipal Environmental Protection Bureau of Urumqi. Data about health indexes was obtained from daily case records of four AAA-level large hospitals in four districts of Urumqi. The relevant information about medical insurance was provided by the Social Security Bureau of Urumqi. Meteorological data was collected from information released by the weather stations of the Xinjiang Uygur Autonomous Region.

\section{Value assessment and compensation of health hazards}

General health conditions of urban residents

As shown in Fig. 3, a high correlation was observed between the respiratory disease mortality, the incidence of chronic bronchitis, the incidence of acute bronchitis, the emphysema incidence, asthma incidence; and the change trends in $\mathrm{PM}_{10}$ and $\mathrm{SO}_{2}$. 


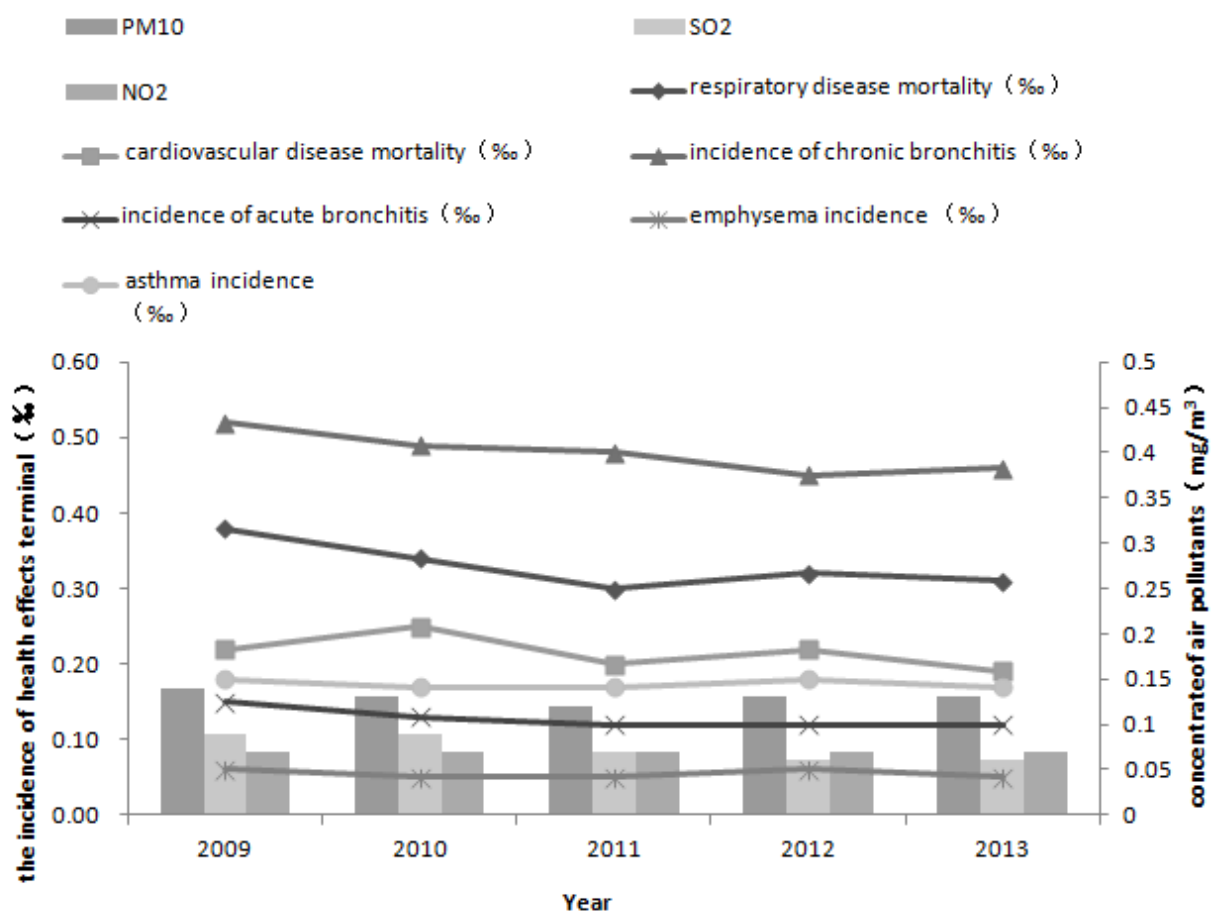

Figure 3. Incidence of various health effect terminals of air pollution in Urumqi (2009-2013)

Incidence of various diseases caused by air pollution

Changes in daily concentrations of pollutants including $\mathrm{PM}_{10}$ and $\mathrm{SO}_{2}$ and incidences of different diseases in 2013 were respectively plugged into Equation (1) and (2) to calculate their relative risks to different diseases and confidence intervals. As shown in Table 3, relative risks of $\mathrm{PM}_{10}$ to respiratory and cardiovascular diseases were much higher than those of $\mathrm{SO}_{2}$, while relative risks of $\mathrm{SO}_{2}$ to acute bronchitis, asthma and other diseases were much higher than those of $\mathrm{PM}_{10}$. In addition, relative risks of both $\mathrm{PM}_{10}$ and $\mathrm{SO}_{2}$ to chronic bronchitis and emphysema were very high.

Table 2. Relative risks of air pollutants to various health hazard terminals and confidence intervals

\begin{tabular}{|c|c|c|c|c|c|c|c|c|c|c|c|c|}
\hline \multirow[b]{2}{*}{ Pollutants } & \multicolumn{2}{|c|}{$\begin{array}{l}\text { Respiratory } \\
\text { disease mortality }\end{array}$} & \multicolumn{2}{|c|}{$\begin{array}{l}\text { Cardiovascular } \\
\text { disease mortality }\end{array}$} & \multicolumn{2}{|c|}{$\begin{array}{l}\text { Chronic } \\
\text { bronchitis }\end{array}$} & \multicolumn{2}{|c|}{$\begin{array}{l}\text { Acute } \\
\text { bronchitis }\end{array}$} & \multicolumn{2}{|c|}{ Emphysema } & \multicolumn{2}{|c|}{ Asthma } \\
\hline & RR & $95 \%$ CI & $\mathrm{RR}$ & $96 \%$ CI & $\mathrm{RR}$ & $97 \% \mathrm{CI}$ & $\mathrm{RR}$ & $98 \% \mathrm{CI}$ & $\mathrm{RR}$ & $99 \% \mathrm{CI}$ & $\mathrm{RR}$ & $100 \% \mathrm{CI}$ \\
\hline $\mathrm{PM}_{10}$ & 1.12 & $1.01-1.62$ & 1.08 & $1.02-1.40$ & 1.31 & $\begin{array}{l}1.12- \\
1.56\end{array}$ & 1.30 & $\begin{array}{l}1.21- \\
1.66\end{array}$ & 1.54 & $\begin{array}{l}1.45- \\
1.66\end{array}$ & 1.38 & $\begin{array}{l}1.14- \\
1.59\end{array}$ \\
\hline $\mathrm{SO}_{2}$ & 0.72 & $0.45-1.33$ & 0.55 & $0.03-2.58$ & 1.32 & $\begin{array}{l}0.41- \\
3.22\end{array}$ & 2.24 & $\begin{array}{l}. .44- \\
7.78\end{array}$ & 1.22 & 2.89 & 4.8 & 14.55 \\
\hline
\end{tabular}

When RR values (relative risks, the incidence of one disease caused by an increase in the concentration of one pollutant in the air) from Table 3 were substituted into Equation (3), it is found that 16.073 people suffered health losses caused by air pollution in Urumqi in 2013 (Table 4). The number of chronic bronchitis patients triggered by $\mathrm{PM}_{10}$ and $\mathrm{SO}_{2}$ was 7,549 , accounting for majority of the population. 
Table3. Numbers of health effect terminals caused by air pollution in Urumqi in 2013

\begin{tabular}{|c|c|c|c|}
\hline Health effect terminals & $\begin{array}{l}\text { Number of health ef } \\
\text { terminals caused } \\
\mathrm{PM}_{10}\end{array}$ & $\begin{array}{l}\text { fect } \\
\text { byNumber of health effect } \\
\text { terminals caused by } \mathrm{SO}_{2}\end{array}$ & Total \\
\hline \multicolumn{4}{|c|}{ Respiratory $\quad$ disease } \\
\hline mortality & 312 & 138 & 450 \\
\hline \multicolumn{4}{|c|}{ Cardiovascular disease } \\
\hline mortality & 211 & 95 & 306 \\
\hline Chronic bronchitis & 5496 & 2098 & 7594 \\
\hline Acute bronchitis & 2150 & 1730 & 3880 \\
\hline Emphysema & 559 & 322 & 881 \\
\hline Asthma & 1920 & 1042 & 2962 \\
\hline
\end{tabular}

\section{Health economic losses of air pollution}

The numbers of various disease patients caused by changes in air pollutant concentrations (Table 4) were substituted into Equations (4), (5) and (6) to calculate health economic losses of air pollution. Urumqi is a medium-developed second-tier city, with a total population of 3.46 million. As shown in Table 5, full-year economic losses of respiratory disease deaths, cardiovascular disease mortality, chronic bronchitis, acute bronchitis, emphysema, andasthmawere 11.934 million yuan, 10.35 million yuan, 22.782 million yuan, 7.76 million yuan, 4.405 million yuan, and 5.924 million yuan, respectively. The total amount of economic losses caused by above-mentioned diseases was up to 63.155 million yuan. Among these diseases, chronic bronchitis caused the greatest economic losses, followed by the respiratory disease and cardiovascular disease. In fact, economic losses calculated in this way covered only direct economic losses of diseases, but excluded indirect economic losses such as patient care, workdelaying fees and mental damage compensations. Therefore, these results represented the minimum health economic losses caused by diseases.

Table 4. Health economic losses caused by air pollution in Urumqi in 2013

\begin{tabular}{|c|c|c|c|c|}
\hline Health effect terminals & $\begin{array}{l}\text { Annual } \\
\text { number of } \\
\text { patients }\end{array}$ & $\begin{array}{l}\text { Number } \quad \text { of } \\
\text { patients trigged } \\
\text { by air pollution }\end{array}$ & $\begin{array}{l}\text { Economic losses } \\
\text { (million yuan) }\end{array}$ & Calculation methods \\
\hline $\begin{array}{l}\text { Respiratory disease } \\
\text { mortality }\end{array}$ & 10726 & 450 & 11.934 & $\begin{array}{ll}\begin{array}{l}\text { Modified } \\
\text { capital } \\
\text { (Equation 4) }\end{array} & \text { method } \\
\end{array}$ \\
\hline $\begin{array}{l}\text { Cardiovascular disease } \\
\text { mortality }\end{array}$ & 7574 & 306 & 10.35 & $\begin{array}{lr}\text { Modified } & \text { human } \\
\text { capital } & \text { method } \\
\text { (Equation 4) } & \end{array}$ \\
\hline Chronic bronchitis & 18916 & 7594 & 22.782 & $\begin{array}{l}\text { Disease incapacitation } \\
\text { method (Equation } 5 \text { ) } \\
\text { Disease cost method }\end{array}$ \\
\hline Acute bronchitis & 92152 & 3880 & 7.76 & (Equation 6) \\
\hline Emphysema & 20730 & 881 & 4.405 & $\begin{array}{l}\text { (Equation 6) } \\
\text { Disease cost method }\end{array}$ \\
\hline Asthma & 70688 & 2962 & 5.924 & (Equation 6) \\
\hline Total & & & 63.155 & \\
\hline
\end{tabular}

Subject, object, standards, and modes of health economic loss compensations

An ecological compensation mechanism is built to eliminate negative economic externalities, thus more profoundly reflecting the principle of fairness and impartiality in economic development and social progress(Du et al.,2004). The key of making ecological compensations is to determine 
stakeholders of ecological compensations, that is, identifying the subject, object, standards and modes of compensations. On the basis of calculations of health economic losses caused by air pollution in Urumqi as described above, an indepth study was conducted on the compensation object, subject, standards and modes (Table 6), so as to provide a scientific basis and reference for developing ecological compensation schemes for air pollution.

Table 5. Summary of compensation mechanisms for health losses caused by air pollution

\begin{tabular}{|c|c|}
\hline Projects & Contents \\
\hline $\begin{array}{l}\text { Compensation } \\
\text { subject }\end{array}$ & $\begin{array}{l}\text { 1. National and local governments; } 2 \text {. Existing enterprises discharging } \\
\text { excessive pollutants in fields such as building materials, thermal power, } \\
\text { metallurgy and coal mining and so on in Urumqi; 3. Motor vehicle owners }\end{array}$ \\
\hline $\begin{array}{l}\text { Compensation } \\
\text { object }\end{array}$ & Residents suffering some diseases and health losses due to air pollution \\
\hline $\begin{array}{l}\text { Compensation } \\
\text { standards }\end{array}$ & $\begin{array}{l}\text { It is recommended that the annual financing volume should not be lower } \\
\text { than } 63.155 \text { million yuan. }\end{array}$ \\
\hline $\begin{array}{l}\text { Compensation } \\
\text { modes }\end{array}$ & $\begin{array}{l}\text { 1. Funds can be raised by levying environment health protection taxes and } \\
\text { governments' allocating special funds. } 2 \text {. For operation and management, } \\
\text { environment health protection funds are set from the medical healthcare } \\
\text { insurance funds to provide subsidies to patients suffering air pollution- } \\
\text { related diseases. } 3 \text {. The existing medical reimbursement procedure is taken } \\
\text { as a reference in the allocation of funds. }\end{array}$ \\
\hline
\end{tabular}

\section{Identifying compensation subject and object}

Following the principle of ecological compensation, governments charge money from parties alleged of air pollution, so as to increase costs of their environment-polluting behaviors, and compensate for parties suffering air pollution hazards. The ultimate goal is reducing the number of parties alleged of air pollution due to their external diseconomies, enhancing social equality and protecting environment(Caldwell et al.,1998). To establish a compensation mechanism for health losses caused by air pollution, the first thing is to figure out "who should be responsible for making compensations", that is, the compensation subject. In accordance with the prevailing principle of "the benefited pays", it is not difficult to identify that the compensation subject of health losses caused by air pollution should be environmental pollution producers and economic interest gainers. At the present stage, building materials, thermal power, metallurgy, coal mining and other enterprises make the greatest impacts on the air quality of Urumqi. These enterprises have a great discharge capacity and require high-energy consumptions, and should be taken as the subjects in compensations for health losses caused by air pollution. Levying environmental protection taxes on all these enterprises would affect corporate development and hinder local GDP growth, so the object of taxation should be limited to enterprises with excessive pollution discharges. By levying taxes in this way, governments can not only compensate for health-damaged people, but also encourage enterprises to increase their funding for pollutant purification. In addition, the vehicle ownership in Urumqi had increased from 150,000 in 2005 to 630,000 in 2013 and shown a strong growth momentum. Therefore, it is quite challenging for Urumqi to significantly improve its air quality in a short period of time. On the other hand, air pollution has complex causes so it should not be simply ascribed to industrial development and vehicle exhaust gas emissions. In fact, besides business owners, local governments and the state are also main beneficiaries of economic development. In view of this, due to the complexity of beneficiaries, governments, as representatives of beneficiaries, should bear the responsibility of compensating for health losses caused by air pollution. Governments can levy taxes on relevant enterprises and people, and establish relevant public funds to compensate for the damaged object, that is, residents suffering health losses.

\section{Calculation of compensation standards}

Identification of compensation standards has long been a key and core issue of ecological compensation research. Economic externalities are 
eliminated by punishing people or enterprises with negative external influence and compensating for damaged external influence, so as to improve the welfare of society as a whole(Knut,1998). At present, common methods used for calculating compensation standards include the market approach, the opportunity cost method, the contingent valuation method, and the ecosystem service value method( Li et al.,2007). The market approach is developed based on market theories and is applied when an explicit supply and demand relation is built. However, it is quite difficult to figure out the supply and demand parties for health effects of air pollution, and impossible to identify the ultimate compensation standards through negotiations between the supply and demand parties(Maynard et al.,1999), so the market approach cannot help to calculate compensation standards. The opportunity cost method and the contingent valuation method are widely accepted as appropriate methods for determining compensation standards. Their advantages include directly compensating for opportunities abandoned by health-damaged residents caused by air pollution, and enabling health-damaged residents to obtain maximum compensation payments by compensation providers. However, these two methods calculate compensation standards on the basis of estimating economic and social development conditions(Tan et al.,2008). Calculation results obtained by the opportunity cost method are often higher than the actual value, as opportunity costs produced by health losses are infinite, involving physical, psychological and social and many other costs. Calculation results obtained by the contingent valuation method are lower than the actual value, because interestdriven power and payment willingness are usually far smaller than compensation-accepting willingness, making it hard to make negotiations and reach agreements. Therefore, in the process of identifying compensation standards for health hazards caused by air pollution, the first step is to use the ecosystem service value method, the human capital method, the disease cost method and other methods to estimate economic losses caused by ecological damages, and then determine the standard of ecological compensations. In this study, the standard of ecological compensations was estimated to be 63.155 million yuan. Due to the limitations of available methods, we only calculated the direct cost produced by disease occurrence, but did not touch upon indirect costs such as time and opportunities. Therefore, this value (63.155 million yuan) can only be used as a reference for compensations. At the later stage, the opportunity cost and contingent valuation method can be used to respectively calculate the upper limit and lower limit of the compensation standard, thus providing a floating space for the compensation standard.

\section{Compensation modes}

Different compensation modes are chosen for different fields. At the present stage, common compensation modes include cash subsidies, tax regulation and funds establishment(Zhuo et al.,2010). In the fields of agriculture and forestry, cash subsidies are provided to farmers who returned grain plots in "Returning Grain Plots for Forestry and Grassland Project" to compensate for grain losses and reforestation investment. Cash subsidies provided to these farmers are equivalent to forestry premium and planting grant in foreign countries. Meanwhile, public funds, such as "forest ecological benefit-compensating funds", can be founded to provide financial support to protect, foster and manage protective forests and special-use forest resources(Matzarakis, 1999; Macmillan,1998). In addition, governments often encourage individuals or enterprises to contribute to environmental protection by means of tax relief. For example, governments have implemented tax deducting and exempting policies for lowemission vehicles(Morello Frosch,2000). However, due to the special nature of the health field and the uncertainty of the damaged party and the benefited party, traditional compensation modes are inapplicable to compensations for health hazards caused by air pollution. A special compensation mode for environmental health hazards should be built on the basis of features and mechanisms of the health care system.

Firstly, as compensation fund-raising channels, governments are required to introduce policies to levy environmental health protection taxes on enterprises with excessive pollutant discharges and vehicles with excessive output volumes. Moreover, governments should also allocate special funds in accordance with their financial conditions to control air pollution and compensate for health losses of residents. Secondly, for management and operation of compensation funds, governments should set up special funds for environmental health protection in the existing health care system, to provide subsidies to patients 
suffering health hazard terminal diseases caused by air pollution. Lastly, in terms of the allocation of compensation funds, patients suffering air pollution diseases can file applications to health care sectors, and receive subsidies after submitting medical certificates and authentication reports from health care sectors.

\section{Security mechanism}

Compared with compensations in forests, rivers and other fields, one of the advantages of the compensation mechanism for health losses is that it has developed to be relatively mature and standardized and has a nation-applicable health care system as its institutional guarantee. However, improving the air quality and enhancing the environment ecological protection awareness of governments, enterprises and individuals through compensations, rather than making economic compensation, are the ultimate goals(Luvsan et al.,2012). Therefore, governments must improve corresponding security mechanisms to achieve the overall goals of sustainable development of local environment and ecology. The central and local governments must establish appropriate management and coordination sectors to provide institutional guarantee for the smooth proceeding of healthy economic loss compensation(Karr et al., 2007). To ensure a rational and legal use of compensation funds, it is quite necessary to build a special supervision sector for collecting and using compensation fees. In terms of legal protection, China has initially established systems and regulations related to ecological and environmental protection. However, relevant legal guarantees are far from perfect. More efforts should be devoted to further identifying systems related to collection of pollutant-discharging fees, pollution abatement and license issuance. In terms of institutional guarantee, governments should set up a set of systems for disclosing pollutant discharge volumes of enterprises and individuals, so that the information about main pollutant sources and improvement and pollution abatement effects is available for the public. In addition, supporting systems, such as the compensating informationdisclosing system, the compensation-assessing system, and the system about annual compensation implementation reports, are expected to be gradually established and improved.

\section{CONCLUSIONS}

Due to rapid economic development in China, air pollution has already attracted great attention of people in all social sectors. Therefore, research on health losses has gradually become a hot topic in the academic world. It has been proved by various toxicological and epidemiological studies that air pollutants will inevitably produce a variety of adverse effects on human health. Therefore, estimating health economic losses caused by air pollution can not only help people and governments to have a more accurate understanding of environmental governance costs, but also provide a scientific basis and reference for developing schemes and policies for sustainable development of health in the future. Urumqi is one of the cities suffering quite serious air pollution. As discussed above, although various methods have been used to improve the air quality in recent years, people are still suffering serious air pollution caused by high energy consumption and large pollutant emission volumes. Industry-driven economic development and resulting ecological damages have seriously affected health conditions of urban residents. As the local social and economic development is still inseparable from large-scale energy consumption, it is impossible for Urumqi to make a qualitative change of its coal-based energy development and utilization pattern. Therefore, with a premise of ensuring economic growth, the top priority in future research is to explore how to build an appropriate compensation mechanism, effectively reduce the health economic burdens of people, guide the urban atmospheric environment to change for the better, and realize an overall improvement in health conditions of people.

\section{ACKNOWLEDGMENT}

Many thanks for funding from Natural Science Foundation of China and Areas of Natural Science Foundation committee to support project. At the same time, I greatly appreciate both reviewing experts help and that of the referees concerning improvement to this paper. Thanks again. Fund project supported by the National Natural Science Foundation of China (71463056); Xinjiang Natural Science Foundation (2015211B026). 


\section{REFERENCES}

1. Adel M.R. (2015), 'Estimating the health risks associated with air pollution in Baghdad City', Iraq. Environ Monit Assess, 187, 4203.

2. Ayres-Sampaio D., Teodoro A.C., Sillero N., Santos C., Fonseca J(2014), 'An investigation of the environmental determinants of asthma hospitalizations: an applied spatial approach'. Appl Geogr, 47, 10-19

3. Burnett R.T., Smith-Doiron M., Stieb D., Cakmak S(1999), 'Effects of particulate and gaseous air pollution on cardio respiratory hospitalizations'. Archives of Environmental Health, 54(2), 130-139.

4. Bale, Malcolm D., Greenshields, Bruce L.(1978), 'Japanese Agricultural Distortions and Their Welfare Value'. American Journal of Agricultural Economics,60(1),59-76

5. Caldwell J., Woodruff T., Morella F.R., Axelrod D.(1998), 'Application of health information to hazardous air pollutants modeled in EPA's cumulative exposure project'. Toxicology and Industrial Health, 14 (3), 429-454.

6. Cannon J.S.(1990), 'The health costs of air pollution: a survey of studies published 19841989',Wanshington,DC: American Lung Association.

7. Du Y. J., Jin X.L.(2004), 'The impact of smoke pollution on respiratory symptoms and diseases occur'. China Health Education, 20(6),543-544.

8. Freitas M.C, Almeida S.M., Pacheco A.M.(2009), 'Characterization of the seasonal exposure to air pollutants for a respiratory epidemiological study'. J Radioanal Nucl Chem ,281,219-223

9. Sefton J. A. et al.(1996), 'The net national product and exhaustible resources: The effects of foreign trade'. Journal of Public Economics, 1(61),21-47

10. Kan H.K., Chen B.H.(2002),'Research component of urban air pollution on the health effects of a 10year review'. CHINESE JOURNAL OF PREVENTIVE MEDICINE, 36(1),59-61.

11. Kan H., Chen B.(2004), 'Particulate air pollution in urban areas of Shanghai, China: health-based economic assessment'. Sci Total Environ, 322(3), 71-79

12. Karr C., Lumley T., Schreuder A., Davis R., Larson T., Ritz B., Kaufman J.(2007), Effects of subchronic and chronic exposure to ambient air pollutants on infant bronchiolitis. Am J Epidermal,165,553-560

13. Knut E.R.(1998),'Social costs of air pollution and fossil fuel use: A macroeconomic approach'. Statistic Norway,6,92-98.

14. Leedey G.P., Dornan Z.B., Filipe V.L.(1997),'Compensation of health injuries caused by ecological hazards'. Medicine and Ecology, 6,25-27.

15. Li K.M.(2008), 'Quantitative analysis of the environmental impact of monetary cost of illness, human capital and opportunity cost method'. China Engineering Consulting, 94(6),58-61.

16. Lipfert F.W.(1993), 'A critical review of studies of the association between demands for hospital services and air pollution'. Environ Health Perspect , 101(2), 229-268

17. Leipert, Christian(1987), 'A Critical Appraisal of Gross National Product: The Measurement of Net National Welfare and Environmental Accounting'. Journal of Economic Issues, 1(21),357

18. Li X.G., Miao H., Zheng H. (2009),'Opportunity cost method in determining the application of ecological compensation criteria-As Hainan Central Mountainous Areas For Example. Journal of Ecology', 29(9),4875-4883.

19. Li Z.H., Liu Y.J., Li W. (2007), 'Preliminary estimates economic losses Datong air pollution and ecological compensation'. Productivity Research,8,60-62.

20. Luvsan M.E., Rue H.S., Tseden P. (2012) , The influence of emission sources and meteorological conditions on $\mathrm{SO}_{2}$ pollution in Mongolia. Atmos Environ, 61, 542-549.

21. Macmillan D., Harley D., Morrison R.(1998),'Costeffectiveness analysis of wood land ecosystem restoration'. Ecological Economics, 27(3),313-324.

22. Matzarakis A., Mayer H., Sczepanski P.(1999), 'Urban air pollution and forests, In: Air pollution VII, WIT PRESS'.Advances in Air Pollution, 6, 303-312.

23. Maynard R.L., Coster S.M.(1999), 'Informing the publicabout air pollution. In S. T. Holgate et al'. (Eds.), Air Pollutionand Community Health (pp. 1019-1033). Sydney:Academic. ISBN 0-12352335-4.

24. Morello F. R., Woodruff T., Axelra D., Caldwell J.(2000), 'Air toxics and health risks in California: the public health implications of outdoor concentrations'. Risk Analysis ,20 (2), 273-291.

25. Ridker R.G.(1967),'Economic costs of air pollution: studies in measurement'. New York:Praeger,1967.

26. Tan J. P., Gerdtham U.G., Carl H. L. (2008),'Societal costs of air pollution-related health hazards: A review of methods and results'. Cost Effectiveness and Resource Allocation, 6,19.

27. USEPA Office of Air and Radiation, Office of Air Quality Planning.Fact Sleet-EPA's Recommended Final Ozone and Participle Matters Standards.67

28. Wang W., Tang D.G., Liu H. J.(2000), 'PM2.5 pollution in China and pollution characteristics'. Environmental Sciences, 13,1-5.

29. William E.,Rees(2003),' Economic Development And Environmental Protection: An Ecological Economics Perspective'. Environmental Monitoring and Assessment,86,29-45

30. Xue Y.C., Zhou Y.X. (2008), 'Air pollution harmful to human health caused economic loss assessment'. China Agricultural University, 10(2),12-13. 
31. Xu W.P., Wei N.B.(2007),'Research on the economic value of the loss of Xi'an air and water pollution on human health damage'. China Population-Resources and Environment,17(4), 7175.

32. Xu X.C., Chen R.J., Kan H.D.(2013), 'Metaanalysis of contingent valuation studies on air pollution-related value of statistical life in China'. China Health Resources, 16(1),64-67.

33. Zhao X. L., Fan H. L., Wang Y. X.(2014), 'Based on modified human capital approach of Beijing health costs of air pollutants evaluated'. China Population·Resources and Environment, 24(3),169176.

34. Zhuo G. Z., Zhao D. T., Zhao J. C.(2010), 'Loss of industrial air pollution in the county assessment based on IPA France Extern mode'. Huazhong University of Science and Technology (Social Science Edition),24(5),81-86.

Received: June 15, 2016;

Accepted: June24, 2016 